\title{
The ability to manipulate ROS metabolism in pepper may affect aphid virulence
}

\author{
Mengjing Sun (1)', Roeland E. Voorrips ${ }^{1}$, Martijn van Kaauwen', Richard G. F. Visser ${ }^{1}$ and Ben Vosman (1)
}

\begin{abstract}
Myzus persicae has severe economic impact on pepper (Capsicum) cultivation. Previously, we identified two populations of $M$. persicae, NL and SW, that were avirulent and virulent, respectively on C. baccatum accession PB2013071. The transcriptomics approach used in the current study, which is the first study to explore the pepper -aphid interaction at the whole genome gene expression level, revealed genes whose expression is differentially regulated in pepper accession PB2013071 upon infestation with these M. persicae populations. The NL population induced ROS production genes, while the SW population induced ROS scavenging genes and repressed ROS production genes. We also found that the SW population can induce the removal of ROS which accumulated in response to preinfestion with the NL population, and that preinfestation with the SW population significantly improved the performance of the NL population. This paper supports the hypothesis that $M$. persicae can overcome the resistance in accession PB2013071 probably because of its ability to manipulate plant defense response especially the ROS metabolism and such ability may benefit avirulent conspecific aphids.
\end{abstract}

\section{Introduction}

Aphids, which belong to the order of Hemiptera, are one of the most destructive plant pests worldwide. Among the more than 4000 described aphid species, over 100 species are reported as economically important pests and are able to damage plant health ${ }^{1}$. Aphid infestation can result in direct damage such as chlorosis, necrosis, wilting, defoliation and, more importantly, indirect damage resulting from aphid transmitted viruses ${ }^{2}$. Most aphid species reproduce asexually under suitable conditions, which leads to rapid population expansion and therefore to difficulties in population control $^{1}$.

Given the fact that aphids have severe negative effects on crop cultivation, the frequent use of chemical pesticides is the major management strategy ${ }^{3}$. However, with growing concern about the negative impact of pesticides on the environment, integrated pest management such as promoting aphid resistant varieties is more and more encouraged $^{4}$. Several resistant crop varieties have been

\footnotetext{
Correspondence: Ben Vosman (ben.vosman@wur.nl)

${ }^{1}$ Plant Breeding, Wageningen University \& Research, P.O. Box 3866700 AJ

Wageningen, Netherlands
}

applied to alleviate aphid problems, such as melon varieties resistant to cotton aphid Aphis gossypii ${ }^{5}$, lettuce varieties resistant to the black current-lettuce aphid Nasonovia ribisnigri ${ }^{6}$ and soybean varieties resistant to the soybean aphid Aphis glycines ${ }^{7}$. Although using resistant varieties is a beneficial strategy to control aphids, the durability of crop resistance is threatened by the evolution of new aphid biotypes which have overcome the resistance ${ }^{8}$. Understanding the interaction between aphids and their host plants, including how the resistance response is induced in resistant plants and how aphids adapt to host plant resistance, may help to keep crop resistance more durable during agricultural application.

Plants may induce defense responses against aphid feeding. The defense responses induced in resistant plants include calcium influxes ${ }^{9}$, accumulation of reactive oxygen species $(\mathrm{ROS})^{10}$, phloem occlusion by specific proteins $^{11,12}$ and callose deposition ${ }^{13}$. ROS have been suggested to play an important role in plant defense responses against biotic stresses. They not only may have a direct toxic effect on aphids ${ }^{14}$, but have also been suggested to mediate defense gene activation and interact 
with other signaling components ${ }^{15}$. Accumulation of ROS in plants could enhance aphid resistance ${ }^{16}$ while impairment of ROS production reduces aphid resistance, e.g. makes the plant more susceptible ${ }^{17}$. For example, greenbug (Schizaphis graminum) feeding on resistant sorghum induced the expression of peroxidase which caused ROS production ${ }^{18}$. Moreover, induction of ROS activity was very high in the resistant wheat after the infestation of Russian wheat aphid (Diuraphis noxia) ${ }^{19}$, while it was low in wheat after the infestation of another $D$. noxia population that had overcome the resistance ${ }^{20}$. As ROS are involved in a large network associated with plant defense responses, it is conceivable that their levels may be affected/regulated by multiple enzymes. It has been proposed that ROS can be produced by various enzymes, such as NADPH oxidases ${ }^{21}$, peroxidases ${ }^{22}$ and oxalate oxidase $^{23}$, and may be removed by ROS-scavenging enzymes like catalase $^{24}$ and superoxide dismutase ${ }^{25}$, or by antioxidants like glutathione ${ }^{26}$.

Pepper (Capsicum spp.) is one of the most important and widely cultivated horticultural crops. However, pepper cultivation is hampered by aphids and the viruses they transmit ${ }^{27}$. One accession of Capsicum baccatum (PB2013071) has been recently identified as a good resistance source to a population of Myzus persicae (the $\mathrm{NL}$ population ${ }^{13}$ ). The resistance of this accession was later found to be (partly) overcome by another population of $M$. persicae (the SW population) ${ }^{10}$. The M. persicae populations performed the same on the plants of susceptible accession PB2013046, while the SW population performed significantly better than the NL population on the plants of accession PB2013071 ${ }^{10}$. The susceptibility of accession PB2013046 to both populations was reflected in electrical penetration graph (EPG) recordings that showed similar feeding activities for both aphid populations on that accession. Additionally, neither aphid population induced ROS on PB2013046. The better performance of the SW population on plants of accession PB2013071 was reflected in longer phloem feeding and a much weaker induction of the defense response. To better understand why the two M. persicae populations, NL (incompatible interaction) and SW (compatible interaction), performed so differently on C. baccatum accession PB2013071, we (1) analyzed gene expression in the compatible and incompatible interaction to identify differentially expressed genes (DEGs) that specifically responded to the virulent and avirulent aphid population respectively, with an emphasis on genes involved in ROS production and scavenging; (2) studied ROS accumulation to investigate whether the SW population of $M$. persicae is able to promote plant susceptibility by suppressing ROS accumulation; and (3) studied the ability of both $M$. persicae populations to induce plant susceptibility for conspecific aphids.

\section{Results}

\section{Transcriptome profiling}

Pepper accession PB2013071 shows resistance to aphids of the $M$. persicae NL population, but is susceptible to aphids of the M. persicae SW population. On this accession aphids of the NL population show a reduced survival and a poor reproduction. Aphids of the SW population encounter much fewer problems in survival and reproduction $^{10}$.

RNA isolated from plants of accession PB2013071 treated with aphids of NL population (NL-infested), SW population (SW-infested) or empty clip cages (control) for $6 \mathrm{~h}$ was subjected to RNA-seq analysis. On average, 7.7 GB clean data (6.7-9.2 GB) per sample were generated (detailed information in Table S1). All the datasets have been submitted to European Nucleotide Archive (ENA) (accession number: PRJEB35311).

Using a false discovery rate (FDR) of 0.01 and a $\mid \log _{2}$ (FoldChange) $\mid \geq 1$, there were 168, 431 and 690 DEGs detected between NL-infested and control plants, between SW-infested and control plants and between NL-infested and SW-infested plants, respectively (Fig. 1a, Table S2).

To validate the results obtained from RNA-seq, the expression level of six genes was measured by QPCR in all nine samples. For each gene, the fragments per kilobase of transcript per million fragments (FPKM) values of transcriptome data exhibited similar expression patterns for all the three treatments compared with the QPCR results (Fig. S1). The correlation coefficient between RNA-seq and QPCR ranged from 0.86 to 1 , indicating that the RNA-seq expression data are reliable.

\section{Genes differentially expressed in response to feeding by both aphid populations}

Among all the DEGs identified from the comparison between NL-infested and control plants and between SWinfested and control plants, only 15 genes were upregulated and 48 genes were downregulated in both comparisons (Fig. 1b, Table S3). GO enrichment analyses of the 15 common upregulated genes responding to both aphid populations showed that five and six genes were predicted to be involved in cellular components (GO:0005575) and biosynthetic processes (GO:0009058), respectively. Among the 48 downregulated genes, genes involved in photosynthesis (GO:0009522, GO:00095223, GO:0009535, GO:0016168) were over-represented ( 26 genes out of 48 ), of which genes encoding chlorophyll $\mathrm{a}-\mathrm{b}$ binding proteins were the main group (21 genes).

\section{Differentially expressed genes specific for feeding of the $\mathrm{NL}$ or the SW population}

Of all genes that were differentially regulated in response to feeding of the two aphid populations, most genes are regulated in a population-specific way, showing 


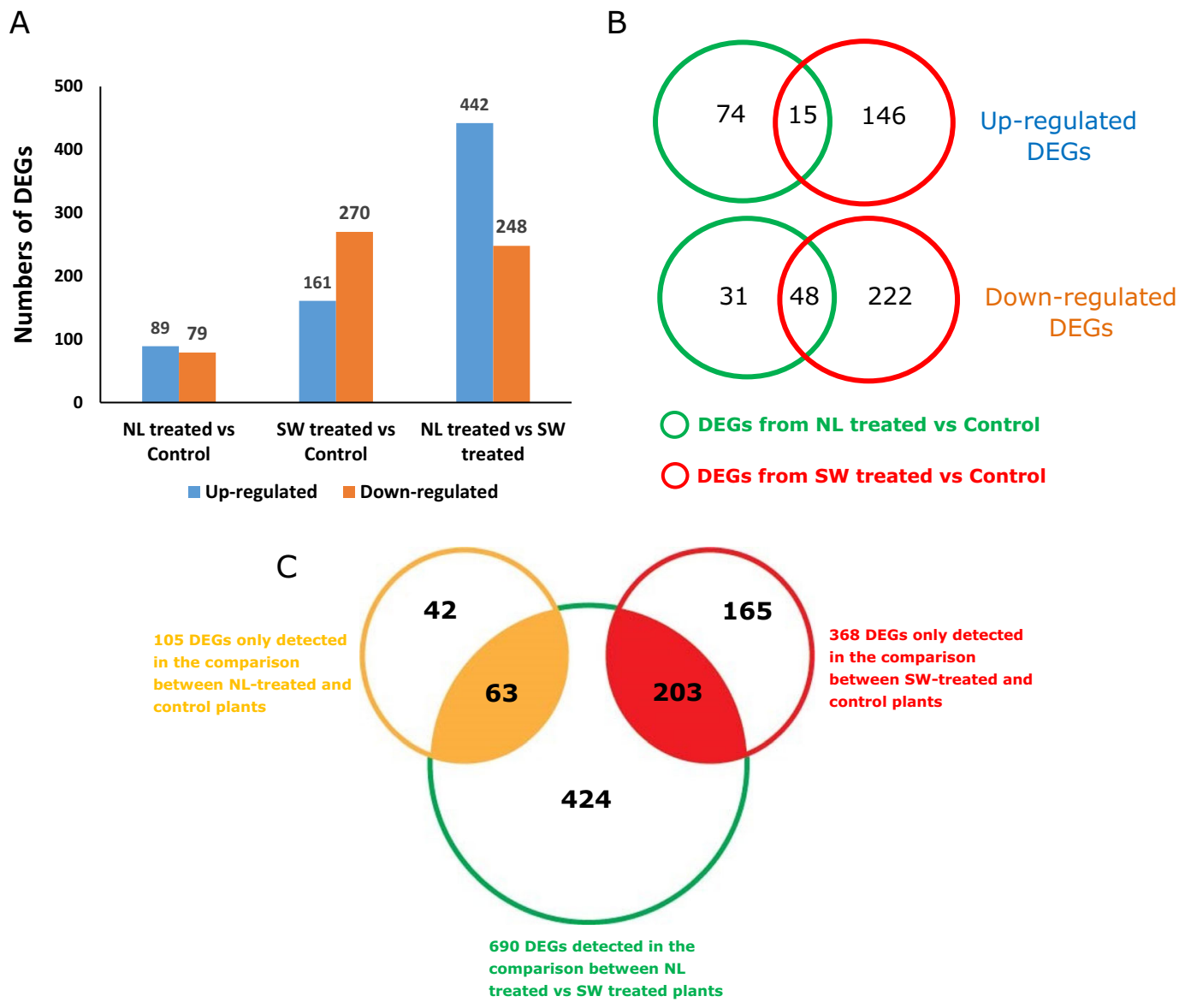

Fig. 1 Differentially expressed genes (DEGs) identified in response to two $M$. persicae populations. Plants received clip cage with aphids of the NL (NL-treated) or SW (SW-treated) population, control plants received an empty clip cage. After a 6-h incubation, leaf disks were harvested and analyzed using RNAseq. The criteria used for assigning significance were: FDR $\leq 0.01$ and $\mid \log 2$ FoldChange $\geq 1$. a Number of upregulated or downregulated DEGs; $\mathbf{b}$ number of DEGs specifically or coexpressed in comparison between control and NL-treated plant as well as in comparison between control and SW-treated plant. c Venn diagram of DEGs that specifically respond to the feeding by the NL or the SW population. DEGs were first compared between the NL-treated vs. control plants and SW-treated vs. control plants. One hundred and five genes were differently regulated in the comparison between NL-treated and control plants (yellow circle) and 368 genes were differently regulated in the comparison between SWtreated and control plants (red circle). The lists of 105 and 368 genes were then compared with the list of 690 DEGs that were detected in the direct comparison between NL-treated and SW-treated plants. The 63 and 203 genes that appeared in both comparisons were considered here to specifically respond to the feeding by the NL and the SW populations respectively.

that transcriptional responses are largely aphid population dependent (Fig. 1b).

When compared with control plants, 105 genes were only significantly up- or down-regulated in the plants that were treated with aphids of the NL population, and 368 genes only after feeding by the SW population (Fig. 1b, Table S4). In a direct comparison between plants that were treated with the NL and SW population, 690 genes were differentially expressed. This list was used to narrow down the number of genes specifically involved in response to different aphid populations. There were 63 genes responding specifically to feeding by the NL population and 203 specifically responding to feeding by the SW population (Fig. 1c,
Table S5). GO enrichment analyses of the 63 genes responding to the NL population indicated that they were mainly involved in oxidoreductase activity (GO:0016491, 19 genes), ion binding (GO:0043167, 19 genes), biosynthetic process (GO:0009058, 11 genes) and response to stress (GO:0006950, 10 genes). The 203 genes specifically responding to SW population were predicted to be mainly involved in different activities such as working in integral component of membrane (GO:0016021, 36 genes), oxidation-reduction processes (GO:0055114, 24 genes), ATP binding (GO:0005524, 19 genes), protein kinase activity (GO:0004672, 18 genes) and phosphorylation (GO:0006468, 18 genes). 


\section{Differentially expressed genes involved in oxidoreductase activity}

We previously observed that aphids of the NL population induce a strong accumulation of ROS, while the SW population induces only a very weak ROS response in plants of PB2013071 $1^{10}$. As we knew from the previous study that differences in ROS accumulation were apparent $6 \mathrm{~h}$ after infestation, the transcriptome analysis of the current study was carried out after $6 \mathrm{~h}$ of infestation. We looked for differences in plant DEGs involved in ROS metabolism, especially in DEGs that specifically responded either to the NL or to SW population (Table S5). Given that ROS production and scavenging is a dynamic oxidation-reduction process, we looked for the DEGs that are assigned with predicted functions related with oxidation-reduction process, which is reflected in the $\mathrm{GO}$ annotations GO:0016491, GO:0016709, GO:0016717, GO:0055114 and GO:0003824.

Among the 63 DEGs that specifically respond to infestation by the NL population, there were 18 upregulated and 4 downregulated genes with oxidoreductase activity (Table 1). Similarly, among the 203 DEGs responding only to the SW population, 14 up- and 16 downregulated were annotated as having oxidoreductase activity (Table 2). Among all DEGs involved in oxidoreductase activity (Tables 1 and 2), only one gene was present in both lists. Peroxidase 12 was upregulated in NL-infested plants while downregulated in SWinfested plants.

\section{Effect of aphid population SW on reactive oxygen species (ROS) metabolism}

In order to explore the effect of the SW population on plant ROS metabolism, we analyzed ROS in pepper leaves of accession PB2013071 after five different treatments, including preinfestations with the NL population.

Plants of accession PB2013071 showed a strong ROS accumulation after 3 days of feeding by aphids of the NL population (Fig. 2a), and this accumulation could not be effectively eliminated by the plants themselves after a further 3-day period with empty cages (Fig. 2b). However, this induced ROS accumulation was mostly eliminated after a subsequent infestation of SW population (Fig. 2c). The reduction in ROS accumulation was reflected by a significantly lower percentage of DAB staining area on the leaf (Fig. 2f, LSD-test, $P<0.05$ ).

Although the presence of the SW aphid population induced a weak ROS accumulation in plants of PB2013071 (Fig. 2d), there was no significant difference in the percentage of stained area between SW-infested leaf and control leaf that received an empty clip cage (Fig. 2d-f, LSD-test, $P>0.05$ ).

\section{Effect of preinfestation with aphid populations on a subsequent infestation}

Besides the RNA-seq analysis and ROS accumulation assays, we also carried out bio-assays to explore whether defense responses induced by the NL population can affect SW performance and whether the manipulation of plant defenses by the SW population could benefit NL population.

Figure 3 shows the effect of preinfestation with the NL population on the performance of the SW population. There was no significant difference in aphid survival and reproduction between living on NL preinfested plants and living on control plants $(t$ test, $P>0.05)$. When the situation was turned around and plants were first infested with aphids of the SW population and the effect on the performance of aphids of the NL population was measured, the outcome was different. Aphids of M. persicae population NL showed a significantly higher survival and produced significantly more next-generation nymphs on SW preinfested plants than on control plants of PB2013071 (Fig. 4, $t$ test, $P<0.01$ ). Preinfestation with the SW population made it possible for the NL aphids to increase survival from $0.35 \pm 0.14$ to $0.78 \pm 0.17$ and to improve reproduction from $2.84 \pm 0.87$ to $4.92 \pm 1.01$ nymphs per original aphid.

\section{Discussion}

Plants show a very different transcriptional response to different conspecific aphid populations

In our previous study we identified two $M$. persicae populations, NL and SW, which are avirulent and virulent on pepper accession PB2013071, respectively. The NL population had difficulties with phloem ingestion and induced a strong defense response, including callose deposition and ROS accumulation in plants of PB2013071, and as a result it was not able to colonize this accession. In contrast, the SW population was able to start sustained phloem intake very easily and only induced a very mild defense response in this accession ${ }^{10}$. In our transcriptome analysis, plants of accession PB2013071 show a very different response to the two M. persicae populations. Of all genes that are differentially regulated in response to feeding of the two aphid populations, $88 \%$ are regulated in a population-specific way (Fig. 1b), and many more genes are regulated only by the SW population than by the NL population (Fig. 1c; 203 vs. 63). This might be simply an effect of the longer sustained feeding of the SW popula$\operatorname{tion}^{10}$, or it could be due to their greater ability to manipulate plant defenses at the gene expression level.

Gene expression among different plant genotypes (resistant/susceptible) in response to one aphid population/clone has been studied frequently ${ }^{28-30}$. Also there are several studies showing the response of one plant 
Table 1 Differentially expressed genes (DEGs) involved in oxidation-reduction processes in resistant $C$. baccatum PB2013071 specifically responding to the NL aphid population.

\begin{tabular}{|c|c|c|c|c|c|c|}
\hline Gene ID & $\begin{array}{l}\text { Control- } \\
\text { average FPKM }\end{array}$ & $\begin{array}{l}\text { NL-treated- } \\
\text { average FPKM }\end{array}$ & log2FoldChange & $\begin{array}{l}\text { Up-down- } \\
\text { regulation }\end{array}$ & FDR & Gene annotation \\
\hline rna5965 & 113 & 475 & 2.07 & Up & $1.88 \mathrm{E}-26$ & Peroxidase N1 \\
\hline rna10318 & 9013 & 23,158 & 1.36 & Up & $1.86 \mathrm{E}-08$ & Peroxidase 12 \\
\hline rna10320 & 1003 & 2596 & 1.37 & Up & 7.59E-07 & Partial Peroxidase 12 \\
\hline rna8690 & 1 & 25 & 4.07 & Up & 0.0048 & Peroxidase 5 \\
\hline rna15242 & 1570 & 4540 & 1.53 & Up & 0.00034 & Linoleate 9S-lipoxygenase 5 \\
\hline rna19402 & 99 & 328 & 1.73 & Up & 0.00036 & $\begin{array}{l}\text { Carotenoid 9,10(9',10')-cleavage } \\
\text { dioxygenase } 1\end{array}$ \\
\hline rna29042 & 66 & 219 & 1.74 & Up & 0.0062 & DMR6-Like oxygenase \\
\hline rna34704 & 78 & 279 & 1.84 & Up & 1.30E-08 & Omega- 6 fatty acid desaturase \\
\hline rna29538 & 136 & 465 & 1.78 & Up & 0.00074 & Omega- 6 fatty acid desaturase \\
\hline rna21402 & 52 & 164 & 1.66 & Up & 0.0014 & Delta(12)-fatty-acid desaturase \\
\hline rna28453 & 64 & 180 & 1.49 & Up & 0.0018 & L-ascorbate oxidase \\
\hline rna24520 & 1176 & 2963 & 1.33 & Up & 0.00084 & Cytochrome P450 76A1 \\
\hline rna10853 & 667 & 1733 & 1.38 & Up & 0.0033 & Cytochrome P450 82A3 \\
\hline rna28819 & 604 & 1588 & 1.39 & Up & 0.0014 & 3-oxoacyl-[acyl-carrier-protein] reductase \\
\hline rna19820 & 157 & 463 & 1.56 & Up & 0.0059 & $\mathrm{NAD}(\mathrm{P}) \mathrm{H}$ : quinone oxidoreductase \\
\hline rna29543 & 1241 & 3277 & 1.4 & Up & 0.0025 & 7-alpha-hydroxysteroid dehydrogenase \\
\hline rna21511 & 69 & 215 & 1.64 & Up & 0.0061 & Arogenate dehydrogenase \\
\hline rna25969 & 68 & 155 & 1.19 & Up & 0.0069 & Aldehyde dehydrogenase \\
\hline rna11857 & 3276 & 794 & -2.04 & Down & $2.03 \mathrm{E}-13$ & Geranylgeranyl diphosphate reductase \\
\hline rna16367 & 810 & 1121 & -1.22 & Down & $1.54 \mathrm{E}-06$ & $\begin{array}{l}\text { NADP-dependent glyceraldehyde-3- } \\
\text { phosphate dehydrogenase }\end{array}$ \\
\hline rna22917 & 68 & 18 & -1.90 & Down & 0.000033 & Cytochrome P450 83B1 \\
\hline rna14689 & 279 & 97 & -1.52 & Down & 0.00042 & Chlorophyllide a oxygenase \\
\hline
\end{tabular}

The criteria used for assigning significance were: FDR $\leq 0.01$ and $\mid \log _{2}$ FoldChange $\mid>1$

genotype to different aphid species ${ }^{31-33}$. However, we found only one report of specific plant gene expression induced by different populations/biotypes of the same aphid species. That report describes the response of wheat to two different biotypes of the Russian wheat aphid ${ }^{34}$. It shows that most wheat genes are regulated in a biotypespecific way, and that one biotype can regulate many more genes than the other, which is similar to our transcriptome results. To our best knowledge, the current study is the first one to explore the interaction between pepper and conspecific aphid populations at the whole genome gene expression level.

To identify genes regulated differently between infestations with the two aphid populations, we used a combination of two approaches. One was to find a set of DEGs comparing noninfested with NL-population-infested plants, and a second set of DEGs comparing noninfested plants with SW-population-infested plants, and then filter for genes occurring in only one of these sets (Fig. 1b). The other approach was to find DEGs in the direct comparison between plants infested with the NL population and plants infested with the SW population. By looking for the DEGs occurring in the datasets of both methods, we found 63 and 203 genes specifically regulated by infestation with the NL population and SW population, respectively (Fig. 1c).

\section{Differentially expressed genes are involved in defense signaling pathways in pepper}

When plants are able to induce defense responses against aphids, multiple signaling pathways may be elicited, including phytohormone-induced pathways ${ }^{35}$. Some genes that are involved in defense signaling pathways are found to specifically respond to feeding by the 
Table 2 Differentially expressed genes (DEGs) involved in oxidation-reduction processes in resistant C. baccatum PB2013071 specifically responding to the SW aphid population.

\begin{tabular}{|c|c|c|c|c|c|c|}
\hline Gene ID & $\begin{array}{l}\text { Control- } \\
\text { average FPKM }\end{array}$ & $\begin{array}{l}\text { SW-treated- } \\
\text { average FPKM }\end{array}$ & log2FoldChange & $\begin{array}{l}\text { Up-down- } \\
\text { regulation }\end{array}$ & FDR & Gene annotation \\
\hline rna4866 & 1154 & 5384 & 2.22 & Up & $1.14 \mathrm{E}-44$ & Catalase \\
\hline rna26330 & 2357 & 6131 & 1.38 & Up & $6.61 \mathrm{E}-30$ & Alanine aminotransferase \\
\hline rna8250 & 161 & 538 & 1.74 & Up & $4.10 \mathrm{E}-22$ & Cytochrome P450 71A6 \\
\hline rna12135 & 37 & 141 & 1.91 & Up & $2.31 \mathrm{E}-09$ & Cytochrome P450 CYP82D47 \\
\hline rna19682 & 37 & 173 & 2.24 & Up & 5.39E-09 & Ferric reduction oxidase 5 \\
\hline rna5789 & 106 & 342 & 1.68 & Up & $1.23 \mathrm{E}-08$ & Cinnamoyl-CoA reductase \\
\hline rna7913 & 286 & 969 & 1.76 & Up & $1.24 \mathrm{E}-07$ & 4-coumarate-CoA ligase 2 \\
\hline rna20326 & 165 & 506 & 1.62 & Up & $3.00 \mathrm{E}-07$ & Ferric reduction oxidase 6 \\
\hline rna2114 & 101 & 250 & 1.31 & Up & $3.21 \mathrm{E}-07$ & $\begin{array}{l}\text { Galactinol-sucrose } \\
\text { galactosyltransferase } 4\end{array}$ \\
\hline rna21997 & 23 & 143 & 2.63 & Up & $1.94 \mathrm{E}-06$ & $\begin{array}{l}\text { Flavonol synthase/flavanone 3- } \\
\text { hydroxylase }\end{array}$ \\
\hline rna8249 & 38 & 124 & 1.70 & Up & 0.000046 & Cytochrome P450 71A6 \\
\hline rna14917 & 246 & 526 & 1.10 & Up & 0.00021 & $\begin{array}{l}\text { Quinone-oxidoreductase } \\
\text { homolog }\end{array}$ \\
\hline rna31209 & 193 & 392 & 1.02 & Up & 0.0030 & Geraniol 8-hydroxylase \\
\hline rna10118 & 331 & 704 & 1.09 & Up & 0.0061 & Cytochrome P450 71A1 \\
\hline rna25419 & 416 & 88 & -2.23 & Down & $1.61 \mathrm{E}-24$ & Cytochrome P450 86A1 \\
\hline rna5501 & 5302 & 1710 & -1.63 & Down & $7.44 \mathrm{E}-23$ & Polyphenol oxidase B \\
\hline rna17709 & 897 & 302 & -1.57 & Down & $2.43 \mathrm{E}-22$ & $\begin{array}{l}\text { Endoplasmic reticulum } \\
\text { oxidoreduction-1 }\end{array}$ \\
\hline rna27753 & 224 & 40 & -2.50 & Down & $2.72 \mathrm{E}-20$ & DMR6-Like oxygenase \\
\hline rna10848 & 863 & 235 & -1.87 & Down & $7.46 \mathrm{E}-19$ & Allene oxide synthase \\
\hline rna14282 & 10875 & 2580 & -2.08 & Down & 4.37E-18 & Beta-carotene hydroxylase 2 \\
\hline rna32427 & 379 & 126 & -1.60 & Down & $2.07 \mathrm{E}-17$ & Alkane hydroxylase MAH1 \\
\hline rna35370 & 1659 & 797 & -1.06 & Down & $5.16 \mathrm{E}-16$ & $\begin{array}{l}\text { Alcohol-forming fatty acyl-CoA } \\
\text { reductase }\end{array}$ \\
\hline rna19821 & 1894 & 762 & -1.32 & Down & $1.02 \mathrm{E}-11$ & $\begin{array}{l}\text { NAD }(\mathrm{P}) \mathrm{H} \text { :quinone } \\
\text { oxidoreductase }\end{array}$ \\
\hline rna23236 & 10323 & 1032 & -3.32 & Down & $2.59 \mathrm{E}-09$ & Protochlorophyllide reductase \\
\hline rna28288 & 214 & 85 & -1.35 & Down & 0.000029 & Cytochrome P450 CYP736A12 \\
\hline rna5811 & 59467 & 28426 & -1.07 & Down & 0.000055 & $\begin{array}{l}\text { Oxygen-evolving enhancer } \\
\text { protein } 1\end{array}$ \\
\hline rna23410 & 304 & 147 & -1.05 & Down & 0.000056 & Delta(8)-fatty-acid desaturase \\
\hline rna20968 & 355 & 147 & -1.27 & Down & 0.000057 & 9-divinyl ether synthase \\
\hline rna10318 & 9013 & 4152 & -1.12 & Down & 0.000112 & Peroxidase 12 \\
\hline rna18808 & 29 & 4 & -2.70 & Down & 0.000140 & Cytokinin dehydrogenase 3 \\
\hline
\end{tabular}



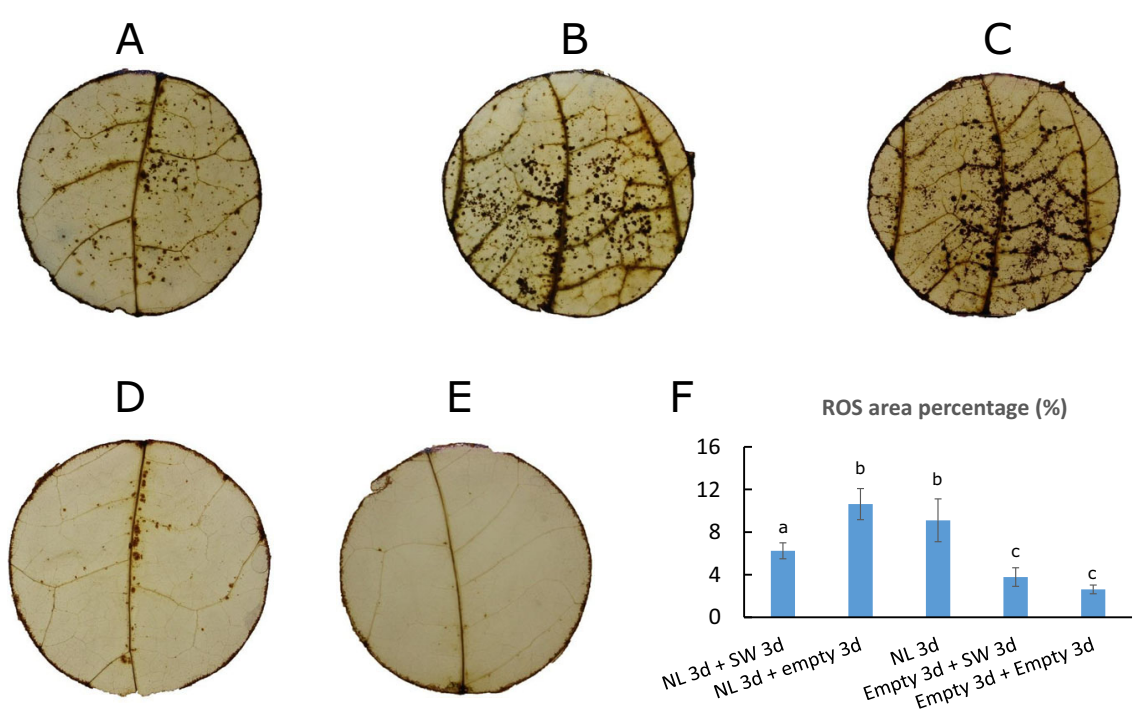

Fig. 2 ROS accumulation in leaves of pepper accession PB2013071 in response to M. persicae populations NL and SW. DAB staining was used to show ROS accumulation after different treatments. a Leaf disk after a 3-day infestation with the NL aphids population. b Leaf disk after a 3day infestation with NL aphids followed by 3 days with an empty cage. c Leaf disk after a 3-day infestation with NL aphids followed by 3 days with the SW aphid population. $\mathbf{d}$ Leaf disk after 3 days with an empty cage followed by 3 days SW population. e Leaf disk after 6 days with an empty cage. $\mathbf{f}$ shows the percentage of stained DAB area calculated per leaf disk under the clip cage area. Bars represent means \pm SD. Different letters indicate statistically significant differences between treatments (LSD-test, $P<0.05$ ).

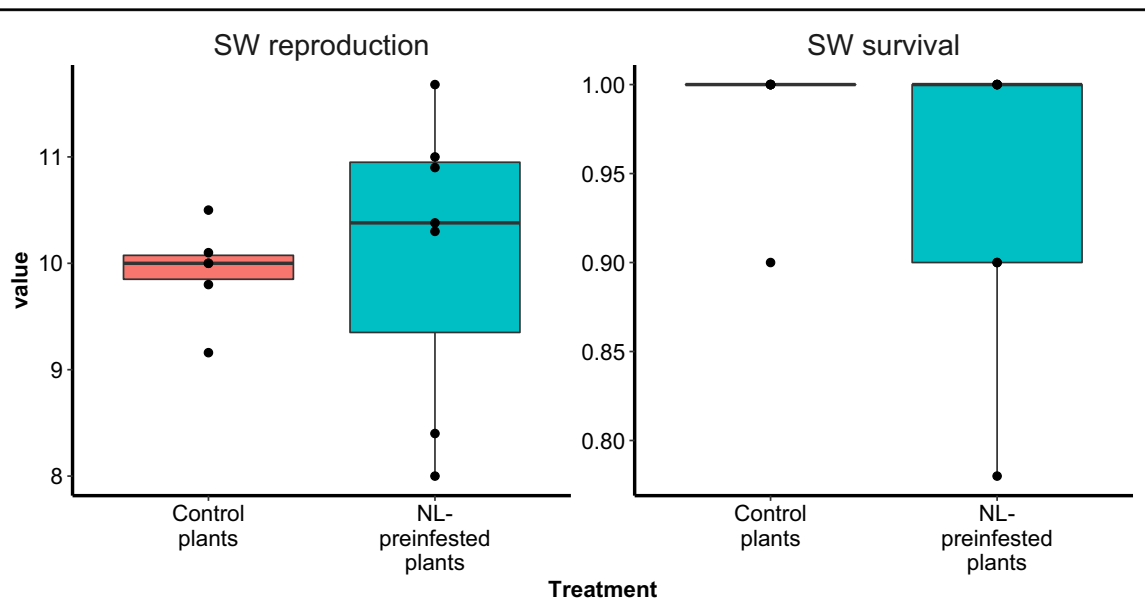

Fig. 3 Performance of the SW population on plants of pepper accession PB2013071. Plants were preinfested with M. persicae of the NL population (NL-preinfested plants) or received an empty clip cage (control plants) for 3 days, after which the aphids were removed. Next, the plants received clip cages with $M$. persicae of the SW population. Two phenotyping parameters were used: average number of next-generation nymphs produced per SW living adult after 12 days (left panel), and the fraction of SW aphids initially put on a plant that survived 12 days (right panel). Seven biological replicates (plants) were used per treatment and are presented as black dots in the box plots. For both phenotyping parameters, no significant difference between the treatments was found ( $t$ test, $P>0.05$ ).

NL and SW populations, respectively (Table S5). For example, linoleate 9S-lipoxygenase (9-LOX, rna15242) is specifically induced by the NL population, and the gene expression level in NL-infested plants is three times higher compared with the one in control plants as well as in SW-infested plants. The 9-LOX gene in pepper can induce responsive genes of salicylic acid (SA) and jasmonic acid pathways (JA), accumulate ROS and therefore enhance resistance to several microbial pathogens ${ }^{36}$. Several genes that are involved in abscisic acid (ABA) pathway are only regulated by infestation with the SW population. The ABA-insensitive 5 (rna20904) gene is 


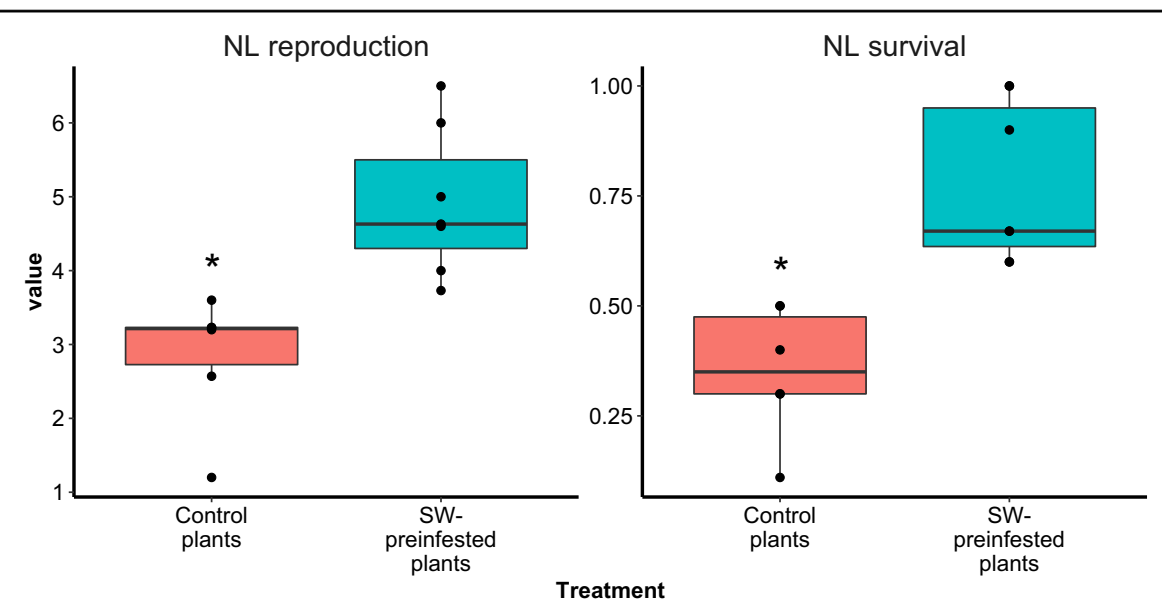

Fig. 4 Performance of the NL M. persicae population on plants of pepper accession PB2013071. Plants were preinfested with the SW population (SW-preinfested plants) or received an empty clip cage (control plants) for 3 days, after which the aphids were removed. Next, the plants received clip cages with aphids of the NL population. Two phenotyping parameters were used: average number of next-generation nymphs produced per living NL adult after 12 days (left panel), and the fraction of NL aphids initially put on a plant that survived 12 days (right panel). Seven biological replicates were used per treatment and are presented as black dots in box plots. For both phenotyping parameters, a significant difference between the treatments was found ( $t$ test, $P<0.01$ ).

upregulated while ABA receptors (rna12809 and rna23680) are downregulated after SW infestation. It has been reported that overexpression of ABA receptors can promote resistance to bacteria ${ }^{37}$, while a loss of function of the ABA-insensitive 5 gene can impair ROS-scavenging activities in Arabidopsis $^{38}$. The upregulation of ABAinsensitive 5 and downregulation of ABA receptors in pepper after feeding by the SW population may help to promote plant susceptibility. It has been shown that a virulent bacterial effector promotes plant susceptibility in Arabidopsis through manipulating the ABA pathway ${ }^{39}$. As genes involved in the ABA pathway are only regulated by the SW population, it is possible that the SW population promotes the colonization on PB2013071 by targeting ABA pathway-related genes.

\section{Differentially expressed genes are involved in ROS accumulation and scavenging in pepper}

Previously we found a correlation between ROS accumulation and plant resistance. The plants of accession PB2013046 could not induce ROS accumulation after the infestation by either the NL or SW population, and they were susceptible to both $M$. persicae populations. The plants of accession PB2013071 induced a strong and mild ROS accumulation respectively after the infestation by the $\mathrm{NL}$ and SW population, and they were more resistant to the NL than the SW population ${ }^{10}$. Based on this work, we speculated that some of the M. persicae population-specific DEGs in plants of accession PB2013071 may be related with ROS induction and scavenging. We identified DEGs involved in ROS metabolism by looking for genes predicted to be involved in oxidation-reduction processes. Among the DEGs that specifically responded to infestation with the NL population are four upregulated genes encoding peroxidases (Table 1), which may be involved in ROS production ${ }^{40}$. Peroxidase-dependent ROS production has been described in several studies before ${ }^{22,41}$. In C. annuum, one peroxidase $(\mathrm{CaPO} 2)$ has been reported to be required for ROS generation and this gene has been found to enhance plant resistance against bacteria ${ }^{42}$ and fungi ${ }^{43}$. So far there have been no reports on the involvement of peroxidase in insect resistance in pepper. The peroxidase 5 (rna8690), which is only upregulated by NL aphids, shares high similarity with $\mathrm{CaPO} 2$ in amino acid sequence (Fig. S2), suggesting that $\mathrm{CaPO} 2$ and rna8690 might be orthologous genes in $C$. annuum and C. baccatum. In addition, the activity of peroxidase 12 has been found to be responsible for ROS accumulation in maize and thereby to enhance resistance to the fungus Ustilago maydis, and inhibition of peroxidase 12 increased the infection rate of $U$. maydis ${ }^{44}$. In our RNA-seq results, peroxidase 12 (rna10318) is the only peroxidase gene that is downregulated in the plants treated with SW aphids, which has been validated by QPCR (Fig. S1). However, maize and pepper are very distantly related species and peroxidase 12 of maize shares only $50 \%$ sequence similarity with that of pepper at the protein level (Fig. S3); therefore, the function of peroxidase 12 may have changed and further work is needed to establish its exact role in pepper. NADPH oxidases have also been suggested to cause ROS accumulation in plantbiotic interactions ${ }^{21,45}$, and higher levels of NADPH oxidase activity have been seen in resistant than in susceptible wheat and maize infested with aphids ${ }^{46}$. A mutation of the NADPH oxidase RBOHD gene in Arabidopsis 
results in decreased ROS accumulation and causes increased $M$. persicae susceptibility ${ }^{47}$. The $R B O H D$ gene in PB2013071 is up- and down-regulated upon infestation by the NL and SW population, respectively, but does not pass the criteria of $\mid \log _{2}$ (FoldChange) $\mid$ in our analysis (0.33 and 0.71 , respectively), which suggests peroxidasemediated ROS production may play a more important role in the pepper-aphid interaction than NADPH oxidase-mediated ROS production, at least after $6 \mathrm{~h}$ of infestation.

Catalase (rna4866) is the most significantly upregulated gene with oxidation-reduction process in plants of PB2013071 that specifically responded to the infestation with the SW aphid population (Table 2). The expression difference of this gene in aphid-infested pepper has also been validated by QPCR (Fig. S1). Catalases are among the fastest enzymes that convert $\mathrm{H}_{2} \mathrm{O}_{2}$ to oxygen and water as they do not require a reductant ${ }^{24}$. Suppression of catalase has been found to enhance ROS levels in response to biotic stress in various plant species such as tobacco $^{48}$ and sorgum $^{49}$. Conversely, higher levels of catalase activity have been shown to increase susceptibility to pathogens ${ }^{50,51}$ and also to M. persicae $e^{52}$. There are three main isoforms of catalases: class I, II and III ${ }^{24,53}$. Class I catalases are highly expressed in mature leaves and include Cat1 of Nicotiana plumbaginifolia ${ }^{53}$ and $N$. tabacum $^{54}$, which showed about $96 \%$ sequence identity to the catalase transcript (rna4866) of PB2013071 (Fig. S4). Based on the role of catalase in ROS metabolism and plant defense, the five times higher expression level of catalase (rna4866) in leaves of PB2013071 infested by SW aphids might be one of the most important reasons why the SW population is able to colonize on pepper accession PB2013071. Serine-glyoxylate aminotransferase and alanine aminotransferase are also found to be upregulated in PB2013071 treated by SW aphid population. They are relevant for glutathione biosynthesis and therefore are involved in ascorbate and glutathione cycle that is the major nonenzymatic ROS scavenging process ${ }^{55}$. The increased activity of serine-glyoxylate aminotransferase has been found to be related with a decrease of ROS accumulation ${ }^{56}$ and also has been found in the plants that interact with pathogens in a compatible way ${ }^{57}$. Additionally, the expression levels of two ferric reduction oxidase genes are also increased. Ferric reduction oxidases participate in the process of $\mathrm{H}_{2} \mathrm{O}_{2}$ production and scavenging ${ }^{58}$, and one ferric reduction oxidase has been shown to block ROS accumulation in Arabidopsis ${ }^{59}$. Therefore, besides catalase the higher expression of aminotransferase and ferric reduction oxidase genes may also contribute to the suppression of ROS accumulation in PB2013071 after the infestation of SW M. persicae population.
In summary, a strong ROS accumulation is induced in PB2013071 after feeding by the NL population, which is most likely caused by the upregulation of several genes promoting ROS accumulation, including peroxidases and $\mathrm{NADPH}$ oxidases. Several ROS-scavenging genes are upregulated in PB2013071 after feeding by the SW population, including catalase and aminotransferases, which may explain the mild ROS accumulation in this acccession.

\section{The ability to suppress ROS accumulation may explain why the pepper resistance is overcome by a virulent $M$. persicae population}

In previous experiments a strong defense response involving ROS accumulation was induced by aphids of the NL population on plants of PB2013071, but only a very weak response by the SW population ${ }^{10}$. In the current study we observed in the SW-infested plants of PB2013071 the downregulation of several genes for enzymes known to have a role in ROS production, and the upregulation of some genes for enzymes known to have a role in ROS scavenging. The ability of the SW population to manipulate ROS metabolism of pepper plants by the RNA-seq data is also reflected by the ROS accumulation experiment combined with preinfestation with the avirulent NL aphid population (Fig. 2). The results show that SW aphids can induce removal of most of the ROS accumulated in response to the preinfestion with $\mathrm{NL}$ aphids. The balance between ROS production and scavenging may determine the strength of the plant defense response ${ }^{60}$. In several studies ROS accumulation has been observed in plants upon interaction with pathogens or insects, and differences in this ROS accumulation are linked with differences in plant resistance ${ }^{14,19}$. Additionally, ROS accumulation in host plants is in several cases linked with the virulence or avirulence of pathogens, such as fungi ${ }^{61}$, bacteria $^{62}$ and nematodes ${ }^{60}$. Only very few studies have been published linking differences in ROS accumulation to differences in virulence among pest insects ${ }^{63,64}$. Our results on ROS accumulation after preinfestation with an avirulent aphid population clearly show the ability of virulent aphids to suppress ROS formation and break down existing ROS. Further validation of this could come from experiments in which key genes involved in ROS accumulation are silenced by virus-induced gene silencing (VIGS) or knocked out by CRISPR. The VIGS technique has been used in the functional analysis of some pepper genes, however until now only in C. annuum ${ }^{65-67}$. So far no VIGS has been reported in C. baccatum. A disadvantage of VIGS in insect studies is also the patchy nature of the silencing, making it easy for aphids to find nonaffected spots on leaves. Alternatives like producing CRISPR knockouts 
have also not been developed yet, due to poor transformability of Capsicum species ${ }^{68}$.

\section{The ability of virulent aphids to manipulate plant defenses may benefit avirulent aphids}

Preinfestation with the NL population does not significantly change the plant response to the subsequent infestation with the SW population (Fig. 3). Based on the fact that plants of PB2013071 induce a strong defense response after infestation with the NL population (Fig. 2) ${ }^{10}$, the noneffect of NL preinfestation to the performance of SW population suggests that the SW population can cope with the plant defense responses induced by the other conspecific aphid.

Preinfestation with the SW population resulted in a significantly better performance of the NL population (Fig. 4), which is reflected in a higher survival of original aphids and higher number of next-generation nymphs produced. The phenomenon that feeding by a virulent aphid population induces susceptibility to a conspecific avirulent population has been also observed in the interaction between soybean and soybean aphid Aphis. glycines $^{69}$ as well as in the interaction between lettuce and the black current-lettuce aphid Nasonovia ribisnigri, although the mechanism of this induced susceptibility remained unclear ${ }^{70}$. Based on our study we can hypothesize that the benefit caused by virulent aphid populations to the conspecific avirulent aphid population might be due to manipulation of plant defense responses, especially the ROS metabolism. The expression level of pepper genes such as catalase that are induced by virulent aphids may remain high after the preinfestation, which might help the following avirulent aphids to start phloem feeding successfully. As we removed the virulent aphids, probably when they were still feeding, it is possible that secreted virulent effectors continued to induce specific pepper genes.

\section{Materials and methods}

\section{Plant material and aphid populations}

C. baccatum accessions PB2013071 and PB2013046 were obtained from the collection of Plant Breeding, Wageningen University \& Research, NL and are described in ref. ${ }^{13}$.

Two weeks after sowing, seedlings were transplanted into $14 \mathrm{~cm}$ pots with potting compost and grown in a standard greenhouse at $19-21^{\circ} \mathrm{C}, \quad 60-70 \%$ relative humidity with an L16:D8 photoperiod at Unifarm, Wageningen University \& Research, NL. Plants were watered every other day. Seven-week-old plants of PB2013071, which were still in vegetative stage, were used in all the experiments.

The two M. persicae populations (NL and SW) used were described previously ${ }^{10}$. The NL population is avirulent on pepper accession PB2013071, while the SW population is virulent. Both populations were reared on susceptible C. baccatum accession PB2013046 in cages in different greenhouse compartments under the same conditions as used for growing the plants.

\section{RNA-seq experiment}

Plants of accession PB2013071 were infested for $6 \mathrm{~h}$ with aphids of the NL (NL-infested) or SW population (SW-infested), or received an empty clip cage (control), after which RNA was extracted (Fig. S5). Each treatment included three biological replicates and three plants were pooled for each replicate. All the used plants were grown in the same greenhouse compartment at the same time. The first three fully expanded leaves from the top of every plant each received one clip cage either with ten randomly selected apterous adults of the NL or SW population, or one empty clip cage. After $6 \mathrm{~h}$ treatment, aphids were gently brushed away from the leaves, and leaf disks under clip cages from one biological replicate (three plants) were quickly sampled and pooled. Leaf disks were flash-frozen in liquid nitrogen and stored at $-80^{\circ} \mathrm{C}$ until use. Total RNA was extracted using the RNeasy Plus Mini Kit (Qiagen, the Netherlands) according to the suppliers' recommendations. RNA quality and quantity were evaluated by NanoDrop 1000 V.3.7 (Thermo, USA), Qubit fluorometric quantitation (Thermo, USA) and agarose gel electrophoresis before sending for RNA-seq analysis.

Library construction and sequencing were performed by Novogene Bioinformatics Technology Co., Ltd (Beijing, China). After cDNA library construction, sequencing was performed on an Illumina HiSeq 2500 system (Illumina, USA) and $2 \times 150$ bp pair-ended reads were generated. In total, at least $6 \mathrm{~GB}$ data were generated per replicate.

\section{Bioinformatic analysis of RNA-seq data}

After the quality of raw data was evaluated by FASTQC $^{71}$, sequence reads of each biological replicate were mapped to the PBC81 C. baccatum reference genome (http://peppergenome.snu.ac.kr/) ${ }^{72}$ using STAR ${ }^{73}$. The number of reads per gene was counted with Salmon (https://combine-lab.github.io/salmon// ${ }^{74}$ and transcript abundance was calculated using the FPKM (fragments per kilobase of transcript per million fragments) method ${ }^{75}$. The SARTools pipeline ${ }^{76}$, which is based on DESeq2 package in $R^{77}$, was employed to detect DEGs between the control treatment and the NL-infested treatment or SWinfested treatment, as well as for the direct comparison between NL- and SW-infested plants. In this pipeline, an FDR analysis ${ }^{78}$ was implemented to correct the $P$ values of the multiple $t$ tests in these comparisons. Genes with a FDR $\leq 0.01$ and $\mid \log _{2}$ (FoldChange) $\mid \geq 1$ were classified as differentially expressed. Blast2GO v5 Basic (https://www. blast2go.com/ $/)^{79}$ was used to carry out gene ontology (GO) analysis to predict the function of DEGs. 


\section{Gene expression validation}

Six genes with differential expression levels based on the RNA-seq data were selected for validation with quantitative real-time PCR. The pepper UBI3 gene (ubiquitinconjugating protein) was used as an internal reference for normalization of gene expression ${ }^{80}$. Gene-specific primers were designed using Primer3Plus (www.bioinformatics.nl/ cgi-bin/primer3plus/primer3plus.cgi) and are listed in Table S6. Each first-strand cDNA was synthesized using the iScriptTM cDNA Synthesis Kit (Bio-Rad, USA) with $1 \mu \mathrm{g}$ RNA. Quantitative RT-PCR was performed in duplicate as described previously ${ }^{13}$. QPCR products were sequenced to verify that the correct fragment was amplified in PB2013071. The relative transcription level of each gene was calculated using the $2^{-\Delta \Delta \mathrm{Ct}}$ method $^{81}$.

\section{Reactive oxygen species (ROS) accumulation experiment}

In order to explore whether the SW population is able to suppress ROS accumulation induced in PB2013071, five different treatments were designed. Three leaves each with one clip cage from five independent biological replicates (plants) were used for each treatment. Four of the five treatments consisted of a preinoculation with either the NL population (15 randomly selected apterous adults in a clip cage) or an empty cage for 3 days. In both cases the clip cage, and if present the aphids, were then removed and replaced at the same place with either an empty clip cage or a clip cage containing 15 apterous adults of the SW population. After this second infestation, lasting again 3 days, the leaves were harvested for observation. In this way four combination treatments were applied (preinfestation-infestation): NL-empty, NL-SW, empty-SW and empty-empty. The fifth treatment consisted of only the preinfestation with NL after which the leaves were harvested directly.

After the treatment leaf disk areas under the clip cage were collected and aphids were gently brushed away if needed. DAB (3,3'-Diaminobenzidine) staining of leaf disks was performed as described ${ }^{10}$. The photos of mounted glass slides with leaf disks were taken with a Canon EOS 100D camera (Canon Inc., Japan). The percentage of the area of brown polymerized deposits, which reflect ROS accumulation on each leaf disk, was quantified using Image ${ }^{82}$. The average percentage from three clip cages that were collected from the same plant was used as the data for one biological replicate. Data were transformed as $\arcsin (\operatorname{sqrt}(x))$ to stabilize the residual variance. The significance of the difference in level of ROS accumulation between the five treatments was evaluated using ANOVA with the LSD test $(P<0.05)$.

\section{Effect of preinfestation on subsequent aphid performance}

A no-choice assay with clip cages was carried out to study whether preinfestation by the NL population had an effect on the performance of SW population on pepper plants of accession PB2013071 and vice versa.

Seven plants of accession PB2013071 were preinfested with three clip cages containing 15 randomly selected apterous adults of the NL population. Another seven plants were similarly preinfested with the SW population. Two control groups of seven plants received three empty clip cages. The cages were placed on first three fully expanded leaves from the top of every plant. Cages were kept on the plants for 3 days, after which the original adult aphids together with offspring were gently removed with a soft brush. Every preinfested plant then received three clip cages containing five 1-day-old nymphs of the aphid population that was different from the population used for preinfestation: NL preinfested plants received SW aphids and vice versa. Plants of two control groups were infested with aphids of either the NL or SW population. The clip cages were put on the same spots on the leaves where the removed clip cages had been. After 12 days the living and dead aphids as well as the next-generation nymphs produced in each clip cage were counted. The observations from three clip cages per plant were combined. Aphid survival and reproduction were determined as described in ref. ${ }^{10}$. For statistical analysis, aphid survival and reproduction were transformed as $\arcsin (\operatorname{sqrt}(x))$ and $\operatorname{sqrt}(x)$, respectively, to stabilize the residual variance. A $t$ test was used to compare the difference in aphid survival and reproduction on preinfested and control plants $(P<0.05)$.

\section{Acknowledgements \\ The research was funded by the Ministry of Economic Affairs of the Netherlands (PPS 1409-029) under the Research Programme Groene \\ Veredeling (Green Breeding) as well as the breeding companies Syngenta B.V., the Netherlands and BASF Vegetable Seeds, the Netherlands. M.S. is supported by a grant from the China Scholarship Council. We would like to thank Mr. Paul Piron for M. persicae identification, Mr. Sean Geurts and Mr. Maarten Peters from Unifarm (Wageningen University \& Research) for taking care of the plants.}

\section{Author contributions}

M.S., B.V. and R.E.V. designed the experiments, which were carried out by M.S. M.S. and M.v.K. carried out the data analysis. M.S., R.E.V., M.v.K. and B.V. drafted the manuscript with comments from R.G.F.V. being included.

Conflict of interest

The authors declare that they have no conflict of interests.

Supplementary Information accompanies this paper at (https://doi.org/ 10.1038/s41438-019-0231-6).

Received: 3 July 2019 Revised: 13 November 2019 Accepted: 4 December 2019

Published online: 01 January 2020

\footnotetext{
References

1. Blackman, R. L. \& Eastop, V. F. Aphids on the World's Herbaceous Plants and Shrubs, 2 Volume Set (John Wiley \& Sons, 2008).

2. Eastop, V. Aphids as Virus Vectors 3-62 (Elsevier, 1977).
} 
3. Perring, T. M., Gruenhagen, N. M. \& Farrar, C. A. Management of plant viral diseases through chemical control of insect vectors. Annu. Rev. Entomol. 44 457-481 (1999).

4. Flint, M. L. \& Van den Bosch, R. Introduction to Integrated Pest Management (Springer Science \& Business Media, 2012).

5. Pitrat, M. \& Lecoq, $H$. Inheritance of resistance to cucumber mosaic virus transmission by Aphis gossypii in Cucumis melo. Phytopathology 70, 958-961 (1980).

6. Eenink, A., Groenwold, R. \& Dieleman, F. Resistance of lettuce (Lactuca) to the leaf aphid Nasonovia ribis nigri. 1. Transfer of resistance from $L$. virosa to $L$. sativa by interspecific crosses and selection of resistant breeding lines. Euphytica 31, 291-299 (1982).

7. Wu, Z., Schenk-Hamlin, D., Zhan, W., Ragsdale, D. W. \& Heimpel, G. E. The soybean aphid in China: a historical review. Ann. Entomol. Soc. Am. 97, 209-218 (2004)

8. Hill, C. B., Crull, L., Herman, T. K., Voegtlin, D. J. \& Hartman, G. L. A new soybean aphid (Hemiptera: Aphididae) biotype identified. J. Econ. Entomol. 103, 509-515 (2010).

9. Vincent, T. R. et al. Interplay of plasma membrane and vacuolar ion channels, together with BAK1, elicits rapid cytosolic calcium elevations in Arabidopsis during aphid feeding. Plant Cell 29, 1460-1479 (2017).

10. Sun, M., Voorrips, R. \& Vosman, B. Aphid populations showing differential levels of virulence on Capsicum accessions. Insect Sci., https://doi.org/10.1111/17447917.12648 (2019)

11. Kehr, J. Phloem sap proteins: their identities and potential roles in the interaction between plants and phloem-feeding insects. J. Exp. Bot. 57, 767-774 (2006).

12. Peng, H. C. \& Walker, G. P. Sieve element occlusion provides resistance against Aphis gossypii in TGR-1551 melons. Insect Sci., https://doi.org/10.1111/17447917.12610 (2018)

13. Sun, M., Voorrips, R., Steenhuis-Broers, G., van't Westende, W. \& Vosman, B. Reduced phloem uptake of Myzus persicae on an aphid resistant pepper accession. BMC Plant Biol., 18, 138 (2018).

14. Liu, X. et al. Reactive oxygen species are involved in plant defense against a gall midge. Plant Physiol. 152, 985-999 (2010).

15. Waszczak, C., Carmody, M. \& Kangasjärvi, J. Reactive oxygen species in plant signaling. Annu. Rev. Plant Biol. 69, 209-236 (2018).

16. Shoala, T., Edwards, M. G., Knight, M. R. \& Gatehouse, A. M. OXI1 kinase plays a key role in resistance of Arabidopsis towards aphids (Myzus persicae). Transgenic Res. 27, 355-366 (2018)

17. Lei, J., Finlayson, S., Salzman, R., Shan, L. \& Zhu-Salzman, K. BOTRYTIS-INDUCED KINASE 1 modulates Arabidopsis resistance to green peach aphids via PHYTOALEXIN DEFICIENT4. Plant Physiol. 165, 1657-1670. (2014).

18. Park, S. J., Huang, Y. \& Ayoubi, P. Identification of expression profiles of sorghum genes in response to greenbug phloem-feeding using cDNA subtraction and microarray analysis. Planta 223, 932-947 (2006).

19. Moloi, M. J. \& van der Westhuizen, A. J. The reactive oxygen species are involved in resistance responses of wheat to the Russian wheat aphid. J. Plant Physiol. 163, 1118-1125 (2006).

20. Botha, A. M., Burger, N. F. \& Van Eck, L. Hypervirulent Diuraphis noxia (Hemiptera: Aphididae) biotype SAM avoids triggering defenses in its host (Triticum aestivum) (Poales: Poaceae) during feeding. Environ. Entomol. 43, 672-681 (2014).

21. Torres, M. A., Dangl, J. L. \& Jones, J. D. Arabidopsis gp91phox homologues AtrbohD and AtrbohF are required for accumulation of reactive oxygen intermediates in the plant defense response. Proc. Natl Acad. Sci. USA 99, 517-522 (2002).

22. Bindschedler, L. V. et al. Peroxidase dependent apoplastic oxidative burst in Arabidopsis required for pathogen resistance. Plant J. 47, 851-863 (2006).

23. $\mathrm{Hu}, \mathrm{X}$. et al. Overexpression of a gene encoding hydrogen peroxidegenerating oxalate oxidase evokes defense responses in sunflower. Plant Physiol. 133, 170-181 (2003).

24. Mhamdi, A. et al. Catalase function in plants: a focus on Arabidopsis mutants as stress-mimic models. J. Exp. Bot. 61, 4197-4220 (2010).

25. Mittler, R., Vanderauwera, S., Gollery, M. \& Van Breusegem, F. Reactive oxygen gene network of plants. Trends Plant Sci. 9, 490-498 (2004).

26. Noctor, G. \& Foyer, C. H. Ascorbate and glutathione: keeping active oxygen under control. Annu. Rev. Plant Biol. 49, 249-279 (1998).

27. Kenyon, L., Kumar, S., Tsai, W. S. \& Hughes, J. Virus diseases of peppers (Capsicum spp.) and their control. Adv. Virus Res. 90, 297-354 (2014).
28. Lee, S. et al. Transcriptomic dynamics in soybean near-isogenic lines differing in alleles for an aphid resistance gene, following infestation by soybean aphid biotype 2. BMC Genom. 18, 472 (2017).

29. Studham, M. E. \& Maclntosh, G. C. Multiple phytohormone signals control the transcriptional response to soybean aphid infestation in susceptible and resistant soybean plants. Mol. Plant-Microbe Interact. 26, 116-129 (2013).

30. Smith, C. M. et al. Aphid feeding activates expression of a transcriptome of oxylipin-based defense signals in wheat involved in resistance to herbivory. J. Chem. Ecol. 36, 260-276 (2010).

31. Alvarez, A. E. et al. Comparative analysis of Solanum stoloniferum responses to probing by the green peach aphid Myzus persicae and the potato aphid Macrosiphum euphorbiae. Insect Sci. 20, 207-227 (2013).

32. Escudero Martinez, C., Morris, J., Hedley, P. \& Bos, J. Barley transcriptome analyses upon interaction with different aphid species identify thionins contributing to resistance. Plant, Cell Environ. 40, 2628-2643 (2017).

33. Jaouannet, M., Morris, J. A., Hedley, P. E. \& Bos, J. I. Characterization of Arabidopsis transcriptional responses to different aphid species reveals genes that contribute to host susceptibility and non-host resistance. PLoS Pathog. 11, e1004918 (2015).

34. Botha, A.-M., Swanevelder, Z. H. \& Lapitan, N. L. Transcript profiling of wheat genes expressed during feeding by two different biotypes of Diuraphis noxia. Environ. Entomol. 39, 1206-1231 (2010).

35. Yates, A. D. \& Michel, A. Mechanisms of aphid adaptation to host plant resistance. Curr. Opin. insect Sci. 26, 41-49 (2018).

36. Hwang, I. S. \& Hwang, B. K. The pepper 9-lipoxygenase gene CaLOX1 functions in defense and cell death responses to microbial pathogens. Plant Physiol. 152, 948-967 (2010).

37. Lim, C. W. \& Lee, S. C. Arabidopsis abscisic acid receptors play an important role in disease resistance. Plant Mol. Biol. 88, 313-324 (2015).

38. Li, X.-Y. et al. Overexpression of Arachis hypogaea AREB1 gene enhances drought tolerance by modulating ROS scavenging and maintaining endogenous ABA content. Int. J. Mol. Sci. 14, 12827-12842 (2013).

39. de Torres-Zabala, M. et al. Pseudomonas syringae pv. tomato hijacks the Arabidopsis abscisic acid signalling pathway to cause disease. EMBO J. 26 1434-1443 (2007)

40. Kawano, T. Roles of the reactive oxygen species-generating peroxidase reactions in plant defense and growth induction. Plant Cell Rep. 21, 829-837 (2003).

41. Daudi, A. et al. The apoplastic oxidative burst peroxidase in Arabidopsis is a major component of pattern-triggered immunity. Plant Cell 111, 093039 (2012).

42. Choi, H. W., Kim, Y. J., Lee, S. C., Hong, J. K. \& Hwang, B. K. Hydrogen peroxide generation by the pepper extracellular peroxidase $\mathrm{CaPO} 2$ activates local and systemic cell death and defense response to bacterial pathogens. Plant Physiol. 145, 890-904 (2007).

43. Choi, H. W. \& Hwang, B. K. The pepper extracellular peroxidase CaPO2 is required for salt, drought and oxidative stress tolerance as well as resistance to fungal pathogens. Planta 235, 1369-1382 (2012)

44. Hemetsberger, C., Herrberger, C., Zechmann, B., Hillmer, M. \& Doehlemann, G. The Ustilago maydis effector Pep1 suppresses plant immunity by inhibition of host peroxidase activity. PLoS Pathog. 8, e1002684 (2012).

45. Desikan, R., Hancock, J. T., Coffey, M. J. \& Neill, S. J. Generation of active oxygen in elicited cells of Arabidopsis thaliana is mediated by a NADPH oxidase-like enzyme. FEBS Lett. 382, 213-217 (1996)

46. Sytykiewicz, H. Deciphering the role of NADPH oxidase in complex interactions between maize (Zea mays L.) genotypes and cereal aphids. Biochem. Biophys. Res. Commun. 476, 90-95 (2016).

47. Miller, G. et al. The plant NADPH oxidase RBOHD mediates rapid systemic signaling in response to diverse stimuli. Sci. Signal. 2, ra45 (2009).

48. Yi, S.-Y., Yu, S.-H. \& Choi, D. Involvement of hydrogen peroxide in repression of catalase in TMV-infected resistant tobacco. Mol. Cells 15, 364-369 (2003).

49. Zhu-Salzman, K., Salzman, R. A., Ahn, J.-E. \& Koiwa, H. Transcriptional regulation of sorghum defense determinants against a phloem-feeding aphid. Plant Physiol. 134, 420-431 (2004).

50. Valenzuela-Soto, J. H. et al. Transformed tobacco (Nicotiana tabacum) plants over-expressing a peroxisome proliferator-activated receptor gene from Xenopus laevis (xPPARa) show increased susceptibility to infection by virulent Pseudomonas syringae pathogens. Planta 233, 507-521 (2011).

51. Palanisamy, S. \& Mandal, A. K. A. Susceptibility against grey blight diseasecausing fungus Pestalotiopsis sp. in tea (Camellia sinensis (L.) O. Kuntze) cultivars 
is influenced by anti-oxidative enzymes. Appl. Biochem. Biotechnol. 172, 216-223 (2014)

52. Divol, F. et al. Systemic response to aphid infestation by Myzus persicae in the phloem of Apium graveolens. Plant Mol. Biol. 57, 517-540 (2005).

53. Willekens, H., Villarroel, R., Van Montagu, M., Inzé, D. \& Van Camp, W. Molecular identification of catalases from Nicotiana plumbaginifolia (L.). FEBS Lett. 352 79-83 (1994).

54. Takahashi, H., Chen, Z., Du, H., Liu, Y. \& Klessig, D. F. Development of necrosis and activation of disease resistance in transgenic tobacco plants with severely reduced catalase levels. Plant J. 11, 993-1005 (1997).

55. De Gara, L., Locato, V., Dipierro, S. \& de Pinto, M. C. Redox homeostasis in plants. The challenge of living with endogenous oxygen production. Respir. Physiol. Neurobiol. 173, S13-S19 (2010).

56. Yang, L. et al. Overexpression of the Arabidopsis photorespiratory pathway gene, serine: glyoxylate aminotransferase (AtAGT1), leads to salt stress tolerance in transgenic duckweed (Lemna minor). Plant Cell, Tissue Organ Cult. (PCTOC) 113, 407-416 (2013).

57. Zamany, A., Liu, J.J. \& Ekramoddoullah, A. K. Comparative proteomic profiles of Pinus monticola needles during early compatible and incompatible interactions with Cronartium ribicola. Planta 236, 1725-1746 (2012).

58. O'Brien, J. A., Daudi, A., Butt, V. S. \& Bolwell, G. P. Reactive oxygen species and their role in plant defence and cell wall metabolism. Planta 236, 765-779 (2012).

59. Einset, J., Winge, P., Bones, A. M. \& Connolly, E. L. The FRO2 ferric reductase is required for glycine betaine's effect on chilling tolerance in Arabidopsis roots. Physiol. Plant 134, 334-341 (2008).

60. Guan, T. et al. Resistance-breaking population of Meloidogyne incognita utilizes plant peroxidase to scavenge reactive oxygen species, thereby promoting parasitism on tomato carrying Mi-1 gene. Biochem. Biophys. Res. Commun. 482, 1-7 (2017)

61. Molina, L. \& Kahmann, R. An Ustilago maydis gene involved in $\mathrm{H} 2 \mathrm{O} 2$ detoxification is required for virulence. Plant Cell 19, 2293-2309 (2007).

62. Gimenez-Ibanez, S. et al. AvrPtoB targets the LysM receptor kinase CERK1 to promote bacterial virulence on plants. Curr. Biol. 19, 423-429 (2009).

63. Elzinga, D. A., De Vos, M. \& Jander, G. Suppression of plant defenses by a Myzus persicae (green peach aphid) salivary effector protein. Mol. Plant-Microbe Interact. 27, 747-756 (2014).

64. Giordanengo, P. et al. Compatible plant-aphid interactions: how aphids manipulate plant responses. C. R. Biol. 333, 516-523 (2010).

65. Kim, K-J. et al. Functional study of Capsicum annuum fatty acid desaturase 1 cDNA clone induced by Tobacco mosaic virus via microarray and virusinduced gene silencing. Biochem. Biophys. Res. Commun. 362, 554-561 (2007).

66. Zhang, Z. et al. VIGS approach reveals the modulation of anthocyanin biosynthetic genes by CaMYB in chili pepper leaves. Front. Plant Sci. 6, 500 (2015).
67. Sarde, S. J. et al. Involvement of sweet pepper CaLOX2 in jasmonatedependent induced defence against Western flower thrips. J. Integr. Plant Biol. 61, 1085-1098 (2019).

68. Kothari, S., Joshi, A., Kachhwaha, S. \& Ochoa-Alejo, N. Chilli peppers-a review on tissue culture and transgenesis. Biotechnol. Adv. 28, 35-48 (2010).

69. Varenhorst, A. J., McCarville, M. T. \& O'Neal, M. E. An induced susceptibility response in soybean promotes avirulent Aphis glycines (Hemiptera: Aphididae) populations on resistant soybean. Environ. Entomol. 44, 658-667 (2015).

70. ten Broeke, C. J., Dicke, M. \& van Loon, J. J. The effect of co-infestation by conspecific and heterospecific aphids on the feeding behaviour of Nasonovia ribisnigri on resistant and susceptible lettuce cultivars. Arthropod-Plant Interact. 11, 785-796 (2017)

71. Andrews, S., FastQC: a quality control tool for high throughput sequence data (2010). http://www.bioinformatics.babraham.ac.uk/projects/fastac.

72. Kim, S. et al. New reference genome sequences of hot pepper reveal the massive evolution of plant disease-resistance genes by retroduplication. Genome Biol. 18, 210 (2017).

73. Dobin, A. et al. STAR: ultrafast universal RNA-seq aligner. Bioinformatics $2 \mathbf{2 9}$ 15-21 (2013).

74. Patro, R., Duggal, G., Love, M. I., Irizarry, R. A. \& Kingsford, C. Salmon provides fast and bias-aware quantification of transcript expression. Nat. Methods $\mathbf{1 4}$ 417 (2017).

75. Trapnell, C. et al. Transcript assembly and quantification by RNA-Seq reveals unannotated transcripts and isoform switching during cell differentiation. Nat. Biotechnol. 28, 511 (2010).

76. Varet, H., Brillet-Guéguen, L., Coppée, J.-Y. \& Dillies, M.-A. SARTools: a DESeq2and edgeR-based R pipeline for comprehensive differential analysis of RNASeq data. PLOS ONE 11, e0157022 (2016).

77. Love, M. I., Huber, W. \& Anders, S. Moderated estimation of fold change and dispersion for RNA-seq data with DESeq2. Genome Biol. 15, 550 (2014).

78. Benjamini, Y. \& Hochberg, Y. Controlling the false discovery rate: a practical and powerful approach to multiple testing. J. R. Stat. Soc. Ser. B (Methodol.) 57, 289-300 (1995).

79. Conesa, A. et al. Blast2GO: a universal tool for annotation, visualization and analysis in functional genomics research. Bioinformatics 21, 3674-3676 (2005).

80. Wan, H. et al. Identification of reference genes for reverse transcription quantitative real-time PCR normalization in pepper (Capsicum annuum L.). Biochem. Biophys. Res. Commun. 416, 24-30 (2011).

81. Livak, K. J. \& Schmittgen, T. D. Analysis of relative gene expression data using real-time quantitative $P C R$ and the $2-\triangle \triangle C T$ method. Methods 25, 402-408 (2001).

82. Collins, T. J. ImageJ for microscopy. BioTechniques 43, S25-S30 (2007). 